\title{
Enteryx polymer migration to lymph nodes and beyond
}

A 39-year-old white man presented with a 2-year history of intermittant, sharp, left-sided chest pain. Two years before, the patient had had an injection of nonresorbable co-polymer (Enteryx; Boston Scientific Corp., Natick, Massachusetts, USA) into the lower esophageal sphincter as a treatment for refractory gastroesophageal reflux disease, and had tolerated the procedure satisfactorily except for mild postprocedural chest pain.

Concerned about an Enteryx-related complication, we ordered a chest radiograph, upper endoscopy, an upper gastrointestinal series, $\mathrm{pH}$-metry and manometry, which were all normal. As we expected, a noncontrast computed tomographic scan of the chest, abdomen, and pelvis revealed polymer around the gastroesophageal junction ( Fig. 1). Unexpectedly, hyperdense material was also seen in the subcarinal region ( $\bullet$ Fig. 2 ) and the right hilum ( $\bullet$ Fig. 3), consistent with polymer migration. In addition, polymer seemed to have migrated to the liver (see - Fig. 1), the spleen, and the wall of the small intestine ( $\bullet$ Fig. 4).

The United States' Food and Drug Administration recalled Enteryx as a result of its association with significant complications, including esophageal abscesses, stenosis, polymer migration, and death [1-4]. Although our patient has evidence of polymer migration to several anatomical sites, this is unlikely to be responsible for his current symptoms. This migration probably occurred at the time of his procedure as a result of inadvertant transmural injection of polymer into blood vessels or lymphatics. The best explanation of our patient's current symptoms is a hypersensitive or irritable esophagus secondary to his Enteryx procedure.

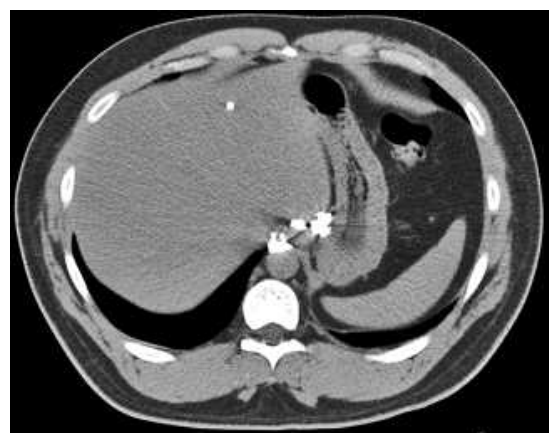

Fig. 1 As expected, computed tomography revealed hyperdense material, consistent in appearance with polymer, around the gastroesophageal junction. A $0.6-\mathrm{cm}$ focus was also seen in the left lower lobe of the liver.

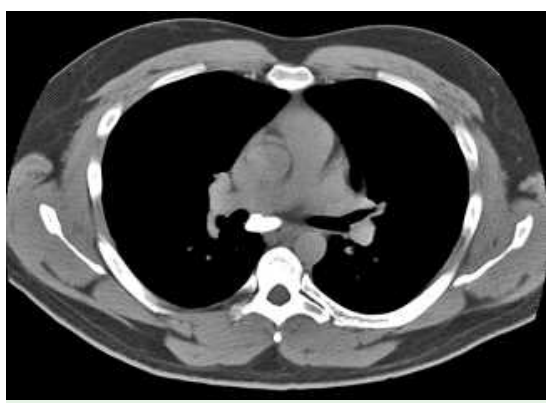

Fig. 2 Another hyperdense focus $(2.7 \mathrm{~cm}$ in transverse diameter and $1.3 \mathrm{~cm}$ in anteroposterior diameter), also consisent in appearance with polymer, was found in the subcarinal node region.

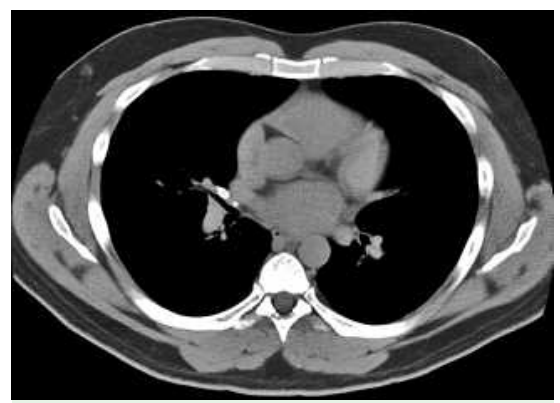

Fig. 3 Further hyperdense foci $(<1 \mathrm{~cm}$ in size) can be seen in the right hilum.

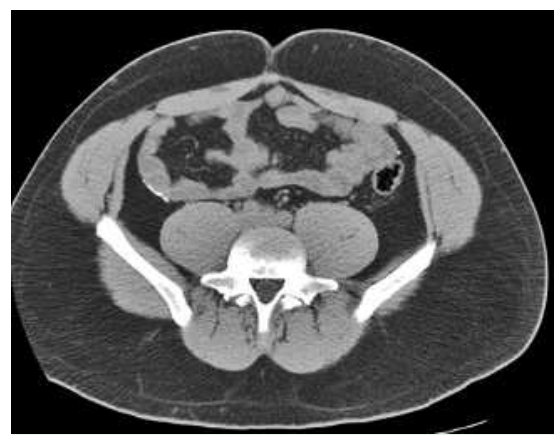

Fig. 4 This image shows hyperdense material suggestive of polymer outlining the wall of a loop of small bowel.

Endoscopy_UCTN_Code_CPL_1AH_2AH

\section{G. R. Veerappan' ${ }^{1}$, J. M. Koff ${ }^{1}$, M. T. Smith ${ }^{1}$}

1 Gastroenterology Service, Department of Medicine, Walter Reed Army Medical Center, Washington, District of Columbia, USA 
References

1 Wong RF, Davis TV, Peterson KA. Complications involving the mediastinum after injection of Enteryx for GERD. Gastrointest Endosc 2005; 61: 753 - 756

2 Iqbal A, Salinas V, Filipi CJ. Endoscopic therapies of GERD. World J Gastroenterol 2006; 12: $2648-2650$

3 FDA Preliminary public health notification: recall of Boston Scientific Enteryx procedure kits and Enteryx injector single packs for the treatment of gastroesophageal reflux disease (GERD). Available from: URL: http://www.fda.gov/cdrh/safety/101405enteryx.html

4 Tintillier M, Chaput A, Kirch L et al. Esophageal abscess complicating endoscopic treatment of refractory gastroesophageal reflux disease by Enteryx injection: a first case report. Am J Gastroenterol 2004; 99: 1856 1858

\section{Bibliography}

DOI $10.1055 / \mathrm{s}-2007-995379$

Endoscopy 2008; 40: E10-E11

(c) Georg Thieme Verlag KG Stuttgart · New York . ISSN 0013-726X

\section{Corresponding author}

G. R. Veerappan, MD

Gastroenterology Service

Department of Medicine

Walter Reed Army Medical Center

6900 Georgia Avenue

Washington 20307

District of Columbia

USA

Fax: +1-202-782-4416

ganesh.veerappan@amedd.army.mil 